\title{
Selection of overburden surface mining method in West Virginia by analytical hierarchy process
}

\author{
Timothy A. Nolan • Vladislav Kecojevic
}

Received: 14 March 2013/Revised: 5 May 2013/Accepted: 5 May 2013/Published online: 20 September 2014

(C) The Author(s) 2014. This article is published with open access at Springerlink.com

\begin{abstract}
The broad objective of this research was to improve current surface mining practices and reduce negative environmental impact of overburden removal in West Virginia (WV). The specific objectives were to (i) compare conventional surface mining method (drilling, blasting, digging, and loading) to a surface miner (SM) method, and (ii) apply the analytical hierarchy process (AHP) to help select the optimal mining method based on production, cost and environmental criteria. The design and the procedures used in this research involve five interrelated modules: (i) rock properties of overburden in WV, (ii) drilling and blasting, (iii) digging and loading, (iv) SM method, and (v) comparative analysis and selection of the optimal mining method by AHP. Results of this research indicate that application of SM method would yield higher cost of overburden removal than conventional mining methods in rocks with a high unconfined compressive strength and abrasivity. A significant advantage of SM method, where applicable, is the elimination of the negative environmental impacts associated with blasting.
\end{abstract}

Keywords Surface mining $\cdot$ West Virginia $\cdot$ Overburden $\cdot$ Production rate $\cdot$ Cost $\cdot$ Environmental impact $\cdot$ AHP model

\section{Introduction}

The current surface mining practices in West Virginia (WV) consist of conventional mining unit operations including: drilling, blasting, digging, loading, haulage, and dumping. Draglines are used in some mines for stripping and direct dumping of overburden material into excavated area.

The WV ranks second in the nation for explosives consumption (Apodaca 2010). Almost 350,000 tonnes were used in WV surface coal mining in 2009. Considering an average price of blasting agents (bulk emulsions, slurry and ANFO) of $\$ 1.14$ per $\mathrm{kg}$, the surface coal mines in WV spent almost $\$ 400$ million for explosives alone. This does not include additional blasting accessories such as detonators, boosters, detonating cords, lead lines, additional

T. A. Nolan · V. Kecojevic ( $₫)$

Department of Mining Engineering, West Virginia University,

Morgantown, WV, USA

e-mail: vlad.kecojevic@mail.wvu.edu costs for labor, explosives truck-delivery, and shot services. The addition of the drilling, digging and loading costs for the blasted material amounts to a significant overall cost to mine operators.

Surface coal mining in WV faces many challenges. These challenges include more restrictive regulations, a negative public perception, and difficult geological formations. Current blasting methods, if not properly designed and conducted, can create hazards like flyrock, toxic fumes, dust, ground vibration, and surface vibration created by airblast. Blasting methods have been refined and are performed in a safer manner but the hazards still remain. Additionally, acid mine drainage may be generated if the rock is not properly identified and segregated. Although these hazards do not occur with every blast, it may only take a few incidents to tarnish the reputation of the entire industry. Exploring and applying alternative safe and environmentally friendly technology provides the potential to minimize if not eliminate these hazards.

The geologic formations in WV consist of overburden and multiple layers of interburden with bituminous coal 


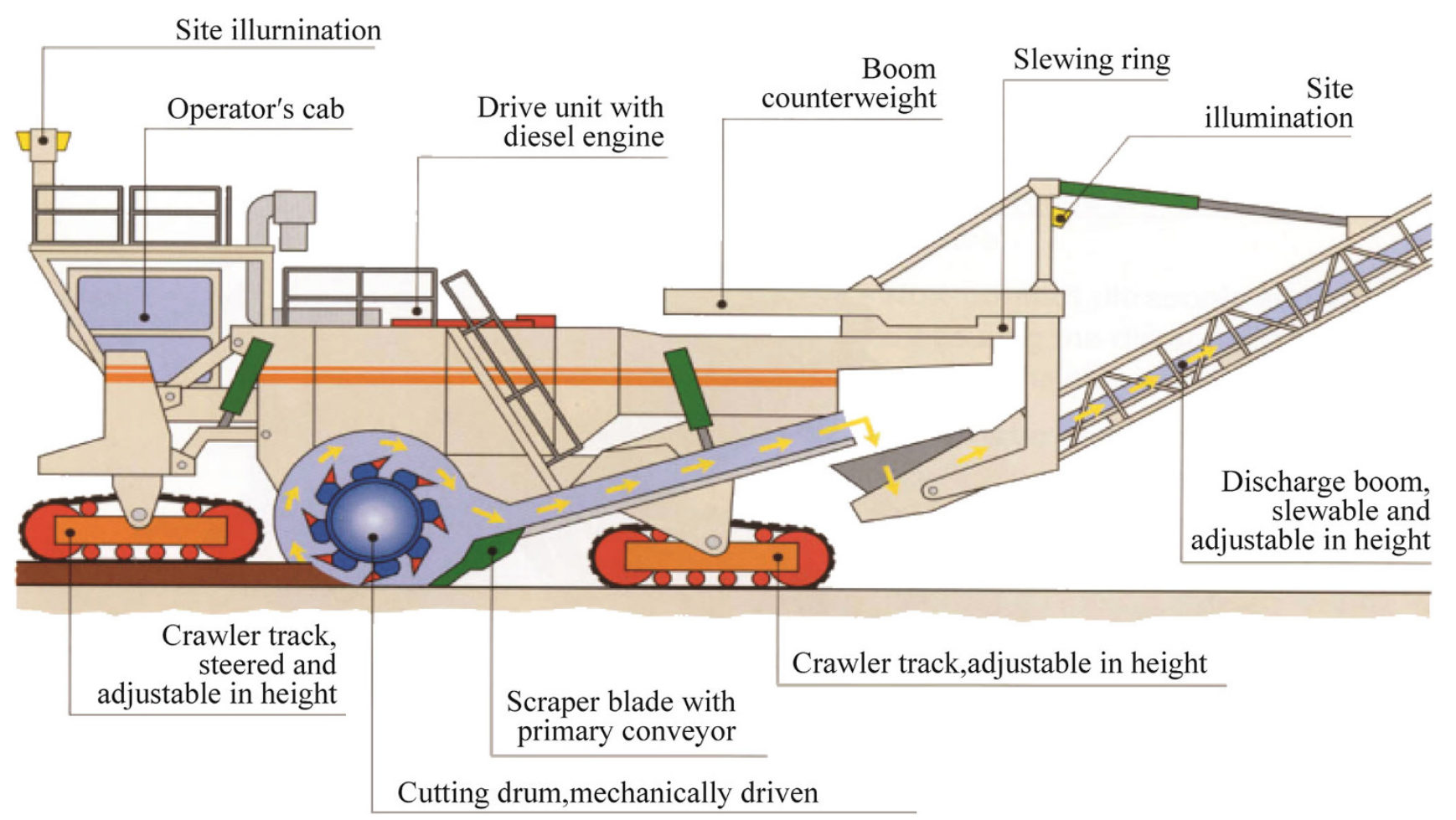

Fig. 1 Surface miner (Wirtgen 2010)

seams of varying thicknesses interspersed between these layers. Overburden and interburden must be removed before the coal is extracted. In most WV surface coal mines several machines are used to dig and load overburden material. This equipment includes hydraulic and electric (rope) shovels, front-end wheel loaders, and draglines (which are used for stripping and dumping into the excavated area). Depending on the thickness of the interburden layers, various methods are used for its removal. Layers with a thickness of generally less than 1.5 meter are ripped by a bulldozer. If the rock is ripped, additional equipment is required to load the material. If the interburden is too thick or too hard to rip, drilling and blasting is required to loosen the rock. The process of ripping or blasting continues with each interburden layer that is encountered in the mine.

More stringent governmental regulations and public pressure are forcing the mining industry to evolve and minimize its environmental impact. Future coal mining operations will need to incorporate new design features and practices that can substantially reduce this impact to achieve "low impact" mining. These design features and practices will be necessary to ensure that the coal industry can design, permit, build, operate, reclaim, and monitor future mines in full compliance with the increasingly stringent environmental performance standards. New mining technologies and systems may minimize environmental disturbances during overburden removal. One of the machines with a potential application in surface mining in $\mathrm{WV}$ is the surface miner (SM). It is a multi-purpose production machine that integrates cutting, crushing, and loading (Fig. 1). It is applied in numerous coal and quarry mining operations around the world.

The broad objective of this research was to improve current surface mining practices and reduce negative environmental impact of overburden removal in WV. The specific objectives were to (i) compare conventional surface mining method (drilling, blasting, digging, and loading) to a SM method, and (ii) apply the analytical hierarchy process (AHP) to help select the optimal mining method based on production, cost and environmental criteria. The text that follows provides a description of the methodology used in this research, results and analysis, and concluding remarks.

\section{Methodology}

The design and the procedures used for achieving the objectives of this research involve five interrelated modules. Module I includes rock properties of sandstone and shale, which are the predominant overburden materials in WV. Module II considers drilling and blasting operations. Module III covers digging and loading of overburden 
material and it specifically addresses mining equipment such as electric and hydraulic shovels, and front-end wheel loaders. Module IV focuses on the SM, while Module V is developed to conduct comparative analyses among all mining unit operations. The entire production and cost model is developed in MS Excel. The AHP is used to help select the optimal mining method based on production, cost and environmental criteria.

The cost and production model for both the conventional and SM mining methods consider a medium-size surface coal mine in WV. For this study, the medium-size mine is defined with a production rate of 7.6 million bank $\mathrm{m}^{3}$ of overburden to be excavated annually.

Module I contains the descriptions of rock types and properties within the state of WV. The typical rock units found in the surface coal mines of WV (generally the majority of the state excluding the eastern panhandle) are sandstone and shale (WVGES 2011). Properties such as bank and loose densities, unconfined compressive strength (UCS), abrasivity expressed through Cerchar Abrasive Index (CAI), seismic wave velocity, and swell factor are compiled from Caterpillar (2010), Hartman (1992); Hartman and Mutmansky (2002), Plinninger (2010), and Rusnak and Mark (2000)

In Module II, equations developed by Atlas Copco (2009), Drake (1990), Austin Powder (2002) and Dyno Nobel (2009) are used to calculate drilling and blasting parameters. These parameters include hole diameter, penetration rate, overall drilling rate, burden, spacing, subdrilling, hole depth, hole length, stemming, particle size for stemming, hole charge length, hole charge concentration, total charge per hole, total amount of explosives, volume of rock per hole, number of required holes, specific drilling, total required drilling, powder factor, and delay times. ANFO and emulsions are the most common explosives agents used in WV surface coal mines, and they are considered in this study. The total drilling and blasting cost is determined.

In module III, production rates for hydraulic shovels, electric (rope) shovels, and front-end wheel loaders are calculated and ownership and operating cost is determined. Various sources such as Caterpillar (2010), Komatsu (2009), Hartman (1992), Kennedy (1990), InfoMine (2010), Runge (1998) and P\&H Mine Pro (2003) are used to determine the production rates and cost. The total cost for each machine is expressed in $\$ / \mathrm{m}^{3}$.

Module IV includes overburden extraction by the SM method. Production rate is given in $t / h$, while the total cost is expressed in $\$ / \mathrm{m}^{3}$. References given by Wirtgen (2010), Origliasso (2011) and InfoMine (2010) are used to determine production rate and cost associated with SM method.

A critical value that must be defined for the SMs is the amount of pick wear. This value is derived from pick wear

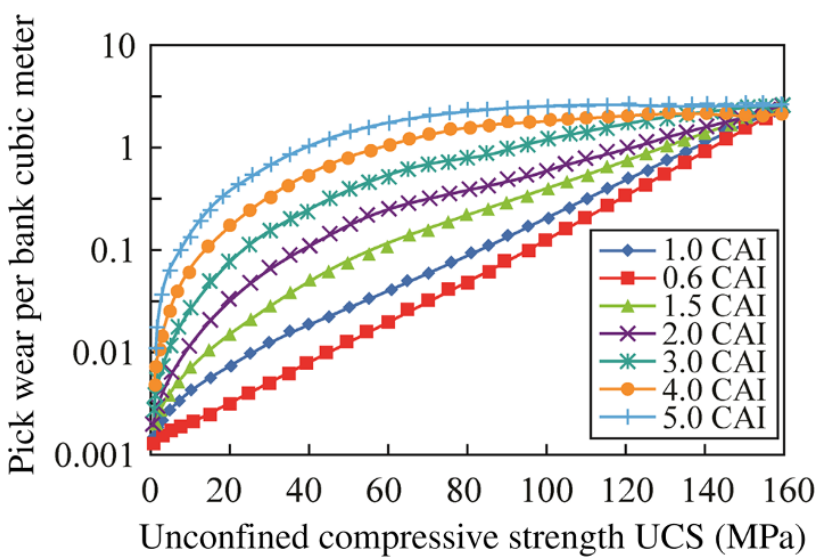

Fig. 2 Pick wear for various values of UCS and CAI

data collected from a road header working in similar conditions. As both machines exert similar forces on the picks, the amount of wear of a road header is fairly transferable to that of a SM (Bauer 2011). The amount of pick wear is dependent on the UCS and CAI. Figure 2 shows graphical representations of the pick wear per bank cubic meter for various values of UCS and CAI. As expected, the more abrasive and the higher the UCS of the rock, the higher wear on the pick. It should be noted that the UCS and abrasivity are not the only factors affecting the amount of pick wear. Properties such as rock structure (solid, fractured, macro/micro seamy), and grain size are a few factors that cause vastly different pick wear values at the same UCS and abrasiveness.

In Module $\mathrm{V}$, the conventional mining method is compared to the SM mining method. To insure both methods are comparable, the total cost is represented in $\$ / \mathrm{m}^{3}$.

The AHP, developed by, Saaty (1980) is used in this research for the selection of the optimal mining method. The process is broken into five levels: (1) goals, (2) strategic issues, (3) criteria, (4) rating scale, and (5) alternatives (Fig. 3).

All five levels are defined and arranged into pairwise comparison matrices. The model developed in this research uses two " $n \times n$ " matrices (one " $3 \times 3$ " matrix for the level two strategic issues and a " $2 \times 2$ " matrix for the level three criteria). No comparison matrix is needed for the production because it only contains one criterion. With these matrices, pairwise comparison is performed. To assign a numerical value to each pair in the matrix, the fundamental scale of absolute numbers created by Saaty (2008) is used in this research.

Eigenvalues, i.e. the priority matrix, are generated from the comparison matrix when each criteria comparison has been given a value. The eigenvalues represent the weights of each criteria considered for the comparison matrix. The higher the weight of a criterion, the higher the influence it 
Level 1: Goal

Selection of optimal mining method

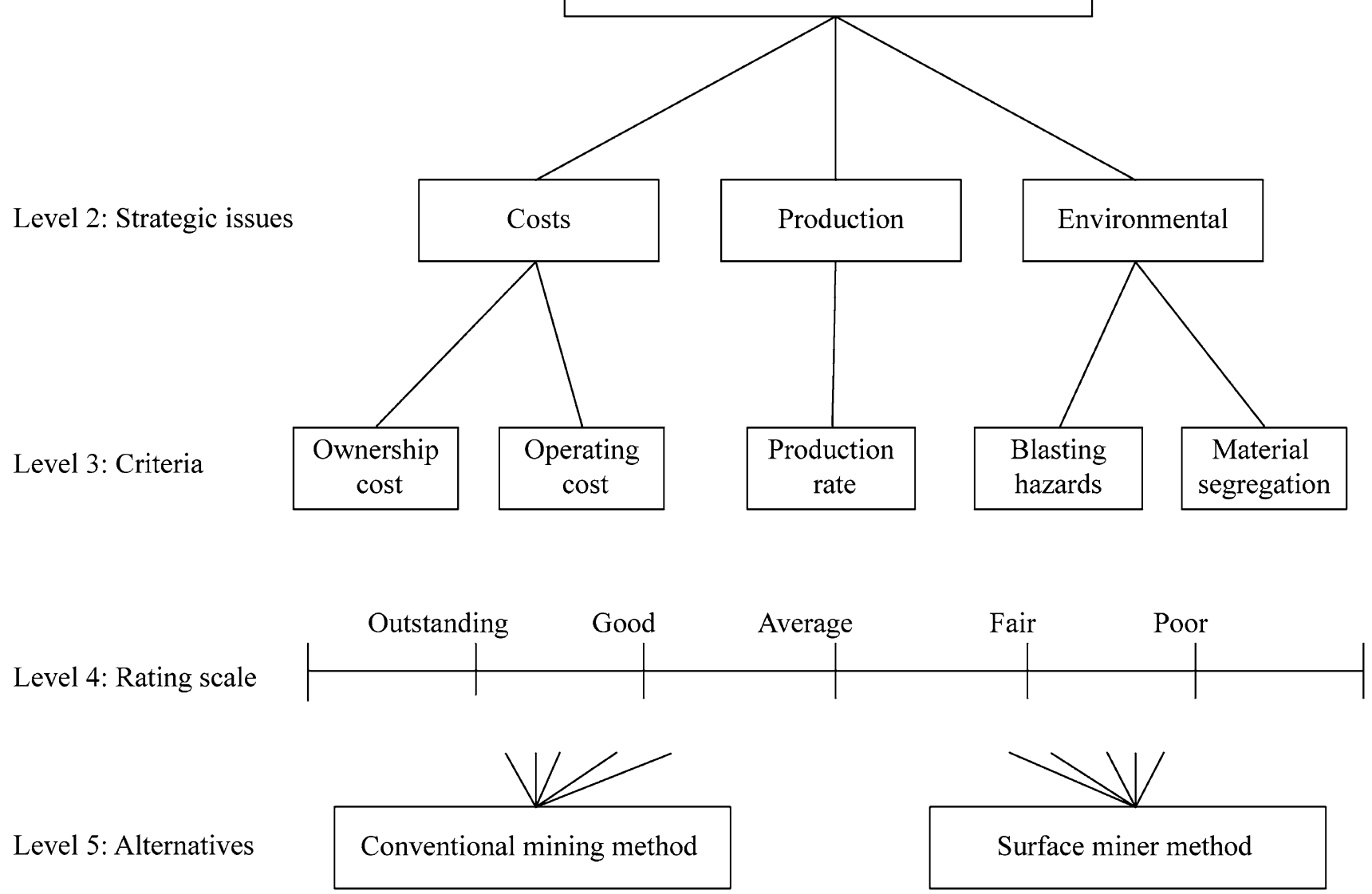

Fig. 3 AHP Model for selection of optimal mining method

will have on the final selection. The priority matrix represents the weight of each criterion. This provides weights for each specific criterion but does not account for the weights of the other level's criteria for the same alternative. The last level of criteria in an AHP model requires global weights $(\mathrm{GW})$ assigned to them. The GW considers each criterion, and its weight, from any previous level. The calculated GW accounts for the local weights of the strategic issue and the criteria. Each alternative combines all GW associated with it and finally the alternative with the highest value will be the best alternative.

To consider the differences between mining methods, it is necessary to rank the criteria for each mining method (Level 4). For this research, the following rating scale is considered: Outstanding (O), Good (G), Average (A), Fair (F), and Poor (P). A rating and score are assigned at the user's discretion to each of the criteria. By multiplying the score and the global weight and summing all these values for each mining method, a total score for the specific mining method is obtained. Finally, after normalizing each total score, the higher score is the determined to be the optimal mining method.
The Consistency Index (CI) is calculated to measure the errors in judgment by the user. This can be explained as the consistency of the user's judgment for each comparison in the matrix. An example of a user with consistent judgments would be as follows: the " $A$ " is deemed more important than " $\mathrm{B}$ "; " $\mathrm{B}$ " is deemed more important than " $\mathrm{C}$ "; and " $A$ " is therefore more important than "C". This type of input into a comparison matrix would display a consistent judgment making process and will likely provide valid results. An inconsistent judgment for the previous example would rate "C" more important than "A".

Finally, Saaty (1980) proposed a method to determine if the matrix is acceptable, by the calculation of the consistency ratio (CR). The $\mathrm{CR}$ is based on the $\mathrm{CI}$ and the consistency indices of randomly generated reciprocal matrices (RI). The CR is calculated based on the " $n$ " value equivalent to the comparison matrix and its corresponding RI value. A general rule for an acceptable matrix is a $\mathrm{CR}$ value less than or equal to 0.10 .

The AHP-based software such as Expert Choice uses the principles described in this methodology. This software is 


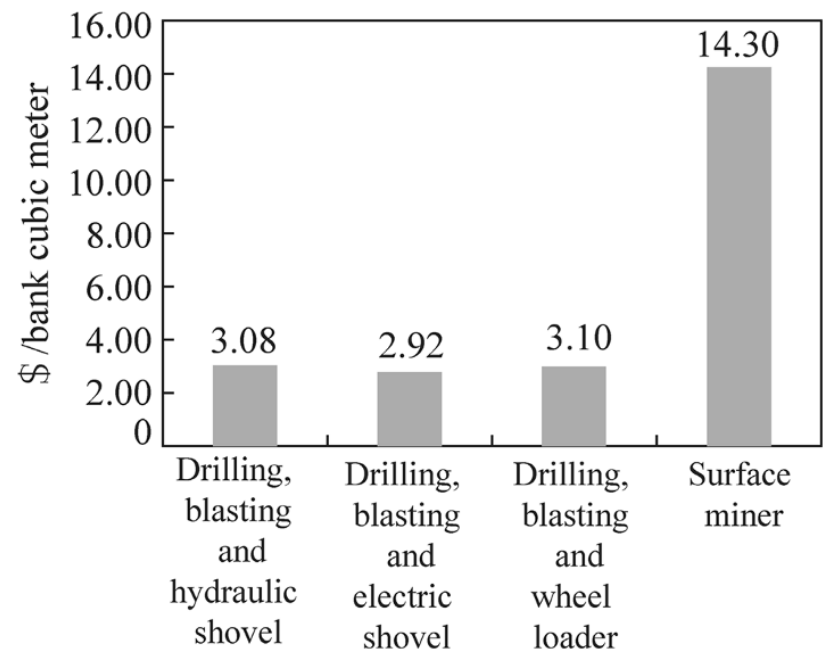

Fig. 4 Conventional versus SM mining method comparison in sandstone overburden

used in this research in order to select optimal mining method. As the AHP results are obtained based on userdefined input values; this approach requires sensitivity analyses to be performed. For this purpose, the same software is also used to adjust the criteria priority, while simultaneously adjusting the remaining criteria relative to each other.

\section{Results and analysis}

For this particular study, bank density of sandstone and shale is considered to be 2,507 and $1,652 \mathrm{~kg} / \mathrm{m}^{3}$, respectively, while loose density is 1,760 and $1,240 \mathrm{~kg} / \mathrm{m}^{3}$, respectively. Specific gravity for sandstone and shale is 2.5 and 1.66, respectively, and swell factor is 1.6 and 1.45 , respectively. For the comparison purposes between conventional mining and SM methods, the UCS for sandstone and shale are selected to be 100 and $75 \mathrm{MPa}$, respectively. The CAI for sandstone and shale is determined to be 2 and 1.5 , respectively. Values of UCS between 60 and $120 \mathrm{MPa}$ for sandstone, and 60 and $100 \mathrm{MPa}$ for shale, are used for various scenarios in determining production rate and cost for SM method. Values of CAI between 0.6 and 5 for sandstone and between 0.6 and 4 for shale are used for various scenarios in determining production rate and cost for SM method. Seismic wave velocity of sandstone and shale is considered to be 2,804 and $1,798 \mathrm{~m} / \mathrm{s}$, respectively.

Figure 4 shows the cost of the extraction of sandstone overburden $(\mathrm{UCS}=100 \mathrm{MPa}$, and $\mathrm{CAI}=2$ ) for four different scenarios: drilling, blasting, and hydraulic shovel (scenario \#1); drilling, blasting, and electric shovel (scenario \#2); drilling, blasting, and front-end loader (scenario \#3); and SM method (scenario \#4). Scenario \#2 yields the

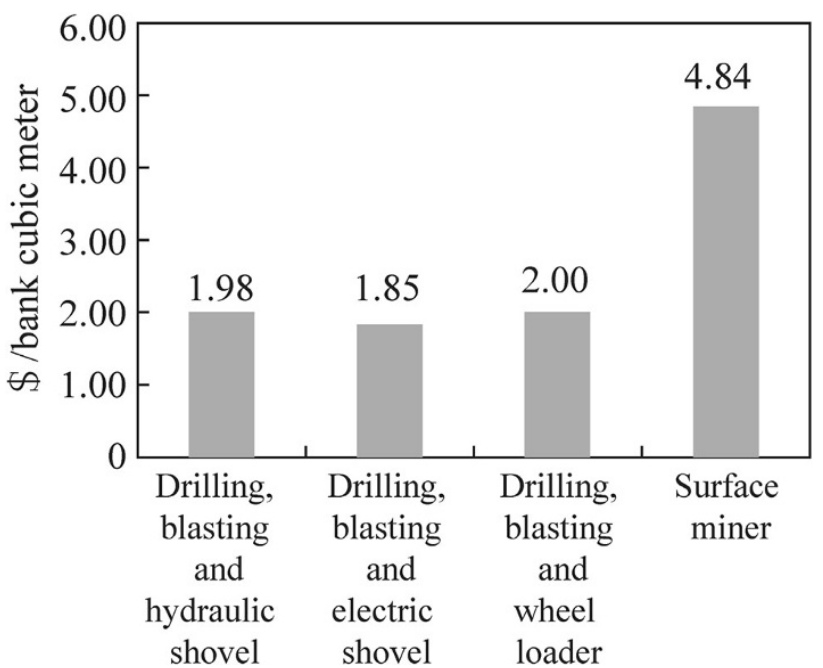

Fig. 5 Conventional versus SM mining method comparison in shale overburden

lowest cost of $\$ 2.92$ per bank $\mathrm{m}^{3}$, followed by, in increasing order, scenario \#1 with the cost of $\$ 3.08$ per bank $\mathrm{m}^{3}$, scenario \#3 with the cost of $\$ 3.10$ per bank $\mathrm{m}^{3}$, and scenario \#4 with the cost of $\$ 14.30$ per bank $\mathrm{m}^{3}$. Scenario \#4, which uses only the SM method, yields higher cost than each of the other scenarios for the considered rock properties.

Figure 5 shows the cost of extraction of shale overburden $(\mathrm{UCS}=75 \mathrm{MPa}, \mathrm{CAI}=1.5)$ for four different scenarios: drilling, blasting, and hydraulic shovel (scenario \#1); drilling, blasting, and electric shovel (scenario \#2); drilling, blasting, and wheel loader (scenario \#3); and SM method (scenario \#4). Once again, scenario \#2 yields the lowest cost of $\$ 1.85$ per bank $\mathrm{m}^{3}$, followed by, in increasing order, scenario \#1 with the cost of $\$ 1.98$ per bank $\mathrm{m}^{3}$, scenario \#3 with the cost of $\$ 2.00$ per bank $\mathrm{m}^{3}$, and scenario \#4 with the cost of $\$ 4.84$ per bank $\mathrm{m}^{3}$. Scenario \#4 yields higher cost when compared to the remaining three scenarios.

The results given in Figs. 4 and 5 provide an estimated comparison that could be expected if the given condition were encountered in the field. While the SM method is more expensive sandstone and shale overburden, it is more expensive in the stronger and more abrasive sandstone than in shale. If the UCS and CAI are found to be lower, the likelihood of using the SM in shale would be higher than in sandstone.

Variations of production rate of the SM in sandstone and shale overburden, based on various UCS and CAI, are given in Tables 1 and 2.

The cost for a varying range of rock properties have been calculated for each of the applications of the SM. The variances in cost, based on the UCS and CAI of the 
Table 1 Surface Miner production rate in sandstone overburden (bank $\mathrm{m}^{3} / \mathrm{h}$ )

\begin{tabular}{lrrrrrrr}
\hline CAI & \multicolumn{6}{l}{ Sandstone (MPa) } \\
\cline { 2 - 8 } & 60 & 70 & 80 & 90 & 100 & 110 & 120 \\
\hline 0.6 & 482 & 378 & 293 & 219 & 158 & 109 & 71 \\
1 & 414 & 320 & 245 & 182 & 132 & 92 & 61 \\
1.5 & 278 & 209 & 157 & 122 & 92 & 68 & 48 \\
2 & 167 & 133 & 110 & 89 & 70 & 54 & 41 \\
3 & 94 & 75 & 63 & 50 & 41 & 34 & 28 \\
4 & 50 & 41 & 34 & 31 & 28 & 25 & 23 \\
5 & 34 & 28 & 24 & 23 & 22 & 21 & 20 \\
\hline
\end{tabular}

Table 2 Surface Miner production rate in shale overburden (bank $\left.\mathrm{m}^{3} / \mathrm{h}\right)$

\begin{tabular}{llrrrr}
\hline CAI & \multicolumn{5}{l}{ Shale $(\mathrm{MPa})$} \\
\cline { 2 - 6 } & 60 & 70 & 80 & 90 & 100 \\
\hline 0.6 & 482 & 378 & 293 & 219 & 158 \\
1 & 414 & 320 & 245 & 182 & 132 \\
1.5 & 278 & 209 & 157 & 122 & 92 \\
2 & 167 & 133 & 110 & 89 & 70 \\
3 & 94 & 75 & 63 & 50 & 41 \\
4 & 50 & 41 & 34 & 31 & 28 \\
5 & 34 & 28 & 24 & 23 & 22 \\
\hline
\end{tabular}

Table 3 Total cost of SM in sandstone overburden (\$/bank $\left.\mathrm{m}^{3}\right)$

\begin{tabular}{lllllrr}
\hline CAI & \multicolumn{6}{l}{ Sandstone $(\mathrm{MPa})$} \\
\cline { 2 - 7 } & 60 & 70 & 80 & 90 & 100 & 110 \\
\hline 0.6 & 0.92 & 1.29 & 1.80 & 2.58 & 3.98 & 6.10 \\
1 & 1.40 & 1.86 & 2.68 & 3.77 & 5.57 & 8.32 \\
1.5 & 2.86 & 4.07 & 5.57 & 7.22 & 9.72 & 13.21 \\
2 & 5.91 & 7.52 & 9.02 & 11.26 & 14.30 & 18.21 \\
\hline
\end{tabular}

Table 4 Total cost of SM in shale overburden $\left(\$ /\right.$ bank $\left.\mathrm{m}^{3}\right)$

\begin{tabular}{llllllr}
\hline CAI & \multicolumn{5}{l}{ Shale $(\mathrm{MPa})$} \\
\cline { 2 - 7 } & 50 & 60 & 70 & 80 & 90 & 100 \\
\hline 0.6 & $\$ 0.72$ & $\$ 0.92$ & $\$ 1.29$ & $\$ 1.80$ & $\$ 2.58$ & $\$ 3.98$ \\
1 & $\$ 0.99$ & $\$ 1.40$ & $\$ 1.86$ & $\$ 2.68$ & $\$ 3.77$ & $\$ 5.57$ \\
1.5 & $\$ 2.05$ & $\$ 2.86$ & $\$ 4.07$ & $\$ 5.57$ & $\$ 7.22$ & $\$ 9.72$ \\
2 & $\$ 4.32$ & $\$ 5.91$ & $\$ 7.52$ & $\$ 9.02$ & $\$ 11.26$ & $\$ 14.30$ \\
\hline
\end{tabular}

overburden being extracted, are displayed in Tables 3 and 4. It can be noted that as the UCS and CAI decreases, the possible application of SM increases.

The comparison of methods uses the values derived by the calculations based on the material properties described
Table 5 Pairwise comparison judgment matrices for the selection of the optimal mining method

\begin{tabular}{lllll}
\hline Goal & Costs & Production & Environmental & Priority \\
\hline Costs & 1 & 0.8 & 0.7 & 0.275 \\
Production & 1.2 & 1 & 0.6 & 0.304 \\
Environmental & 1.4 & 1.5 & 1 & 0.420 \\
& & & & $\mathrm{CR}=0.01$ \\
\hline Cost & \multirow{2}{*}{ Ownership cost } & Operating cost & Priority \\
\hline Ownership Cost & 1 & & 0.9 & 0.476 \\
Operating Cost & 1.1 & & 1 & 0.524 \\
& & & & $\mathrm{CR}=0$ \\
\hline Cost & & Blasting & Material & Priority \\
& & hazards & segregation & \\
\hline Blasting Hazards & 1 & 0.9 & 0.476 \\
Material Segregation & 1.1 & 1 & 0.524 \\
& & & & CR $=0$ \\
\hline
\end{tabular}

Table 6 Composite priority weights for criteria factors

\begin{tabular}{lllll}
\hline Strategic issues & $\begin{array}{l}\text { Local } \\
\text { weights }\end{array}$ & Criteria & $\begin{array}{l}\text { Local } \\
\text { weights }\end{array}$ & $\begin{array}{l}\text { Global } \\
\text { weights }\end{array}$ \\
\hline Costs & 0.275 & Ownership cost & 0.476 & 0.131 \\
& & Operating cost & 0.524 & 0.144 \\
Production & 0.304 & Production rate & 1.000 & 0.304 \\
Environmental & 0.420 & Blasting hazards & 0.476 & 0.200 \\
& & Material segregation & 0.524 & 0.220 \\
\hline
\end{tabular}

in Module \#1. These results should not be taken as a ruleof-thumb for the entire state of WV. In order to ultimately determine what method is the more economical, the site specific material properties must be known and then site specific calculations can be performed and provide a location specific result.

The production and cost comparison presented in this section does not account for the negative or positive environmental factors created by either mining method. The AHP is used to help select the optimal mining method by considering this additional criterion. Since the AHP is based on the user-defined input values, the results are subjective to the user's preferences. To combat the subjective nature of the AHP, a sensitivity analysis of the results is conducted.

The pairwise comparison matrices for the mining method selection can be seen in Table 5. The eigenvalues, or priority matrix, of the comparison matrices yields the priority weights for total cost (ownership and operating), production, and environmental criteria. Finally, a Consistency Ratio (CR) is determined for each comparison matrix and is considered acceptable because it less than 0.10 . 
Table 7 Application of the AHP model for the selection of mining method

\begin{tabular}{|c|c|c|c|c|c|c|c|}
\hline \multirow{2}{*}{$\begin{array}{l}\text { Strategic issues } \\
\text { Criteria }\end{array}$} & \multirow{2}{*}{$\begin{array}{l}\text { Global } \\
\text { weights }\end{array}$} & \multicolumn{3}{|c|}{ Conventional mining method } & \multicolumn{3}{|c|}{ Surface miner method } \\
\hline & & Rating & Score & $\times \mathrm{GW}$ & Rating & Score & $\times \mathrm{GW}$ \\
\hline \multicolumn{8}{|l|}{ Cost } \\
\hline Ownership cost & 0.131 & A & 0.129 & 0.0169 & A & 0.129 & 0.0169 \\
\hline Operating cost & 0.144 & G & 0.261 & 0.0377 & $\mathrm{P}$ & 0.034 & 0.0049 \\
\hline \multicolumn{8}{|l|}{ Production } \\
\hline Production rate & 0.304 & $\mathrm{O}$ & 0.513 & 0.1561 & A & 0.129 & 0.0393 \\
\hline \multicolumn{8}{|l|}{ Environmental } \\
\hline Blasting hazards & 0.200 & $\mathrm{P}$ & 0.034 & 0.0068 & $\mathrm{O}$ & 0.513 & 0.1027 \\
\hline Material segregation & 0.220 & $\mathrm{~F}$ & 0.065 & 0.0143 & $\mathrm{O}$ & 0.513 & 0.1129 \\
\hline Total scores & & & & 0.2318 & & & 0.2767 \\
\hline Renormalized scores & & & & 0.4558 & & & 0.5442 \\
\hline
\end{tabular}

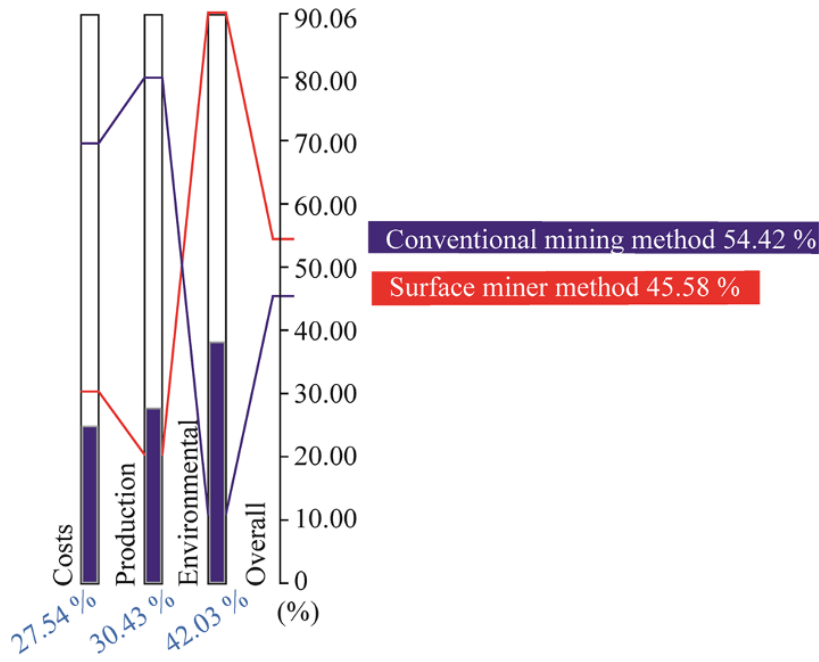

Fig. 6 Comparison between conventional mining and SM methods

The local weights for each strategic issue and criteria are displayed in Table 6. The environmental issues (Blasting hazards and material segregation) have the highest weight due to the level of importance placed on the environmental issues in the comparison matrices.

The global weights show what criteria will have the most effect on the decision making process. Table 7 shows the ratings and scores applied to each of the criteria and the resulting adjusted global weight. The rating scores are as follows: Outstanding $(\mathrm{O})=0.513$; $\operatorname{Good}(\mathrm{G})=0.261$; Average $(\mathrm{A})=0.129 ; \quad$ Fair $(\mathrm{F})=0.063 ;$ and Poor $(\mathrm{P})=0.034$.

The results shown in Table 7 indicate that the SM mining method is the better option due to high weight associated with the environmental strategic issue. Figure 6 shows the results of the AHP with the global weights and scores (in percent) based on results given in Table 7. As each line crosses a strategic issue (cost, production, or environment) it represents the level of importance for that issue. These are simply used to visually assist in understanding the strengths and weaknesses for each mining method. For example, the conventional mining method is more important in terms of cost and production as seen in Fig. 6. The results of performing the AHP provide the global weights for each criterion and the final weight or priority of the alternatives.

Figure 6 displays the global weights of each criterion for cost, production, and environmental as $27.54,30.43$, and $42.03 \%$, respectively. After applying a rating score to each of the criteria the optimal mining method is determined by the highest priority. In this case the SM mining method with $54.42 \%$ is the optimal method compared to $45.58 \%$ for the conventional mining method.

The sensitivity analysis is conducted for three criteria (cost, production, and environmental) in increments of approximately $10 \%$ in both the positive and negative directions. The optimal mining method has the highest priority percentage. The results of these adjustments for the cost criteria can be seen in Table 8. Results show that the optimal mining method selection continues to be the SM mining method until the of cost priority percentage is increased by approximately $20 \%$. This result was expected as the SM has a lower score for cost. A similar trend exists when adjusting the production priority percentage. The optimal mining method remains the SM mining method until the production priority is increased by $10 \%$. This was expected as the SM has a lower score for production and will affect the optimal method at some point. Conversely, as the environmental priority percentage decreases $(-10 \%)$ the optimal mining method becomes the conventional mining method. This was expected as the SM has a higher score for environmental issues and at a point in lowering its priority the optimal mining method will change. 
Table 8 Sensitivity analysis on final criteria (\%)

\begin{tabular}{|c|c|c|c|c|c|c|c|c|c|c|}
\hline \multirow[t]{2}{*}{ Sensitivity analysis } & \multicolumn{4}{|l|}{ Cost } & \multicolumn{3}{|c|}{ Production } & \multicolumn{3}{|c|}{ Environment } \\
\hline & $-10 \%$ & 0 & $\pm 10 \%$ & $\pm 20 \%$ & $-10 \%$ & 0 & $\pm 10 \%$ & $-10 \%$ & 0 & $\pm 10 \%$ \\
\hline Cost & 17.44 & 27.54 & 37.48 & 47.50 & 31.51 & 27.54 & 23.58 & 32.26 & 27.54 & 22.74 \\
\hline Production & 34.67 & 30.43 & 26.26 & 22.05 & 20.41 & 30.43 & 40.45 & 35.64 & 30.43 & 25.13 \\
\hline Environment & 47.88 & 42.03 & 36.26 & 30.45 & 48.08 & 42.03 & 35.98 & 32.10 & 42.03 & 52.13 \\
\hline Surface miner method & 56.12 & 54.42 & 52.52 & 50.33 & 60.87 & 54.67 & 48.43 & 47.47 & 54.67 & 61.21 \\
\hline Conventional mining method & 43.88 & 45.58 & 47.48 & 49.67 & 39.13 & 45.33 & 51.57 & 52.53 & 45.33 & 38.79 \\
\hline
\end{tabular}

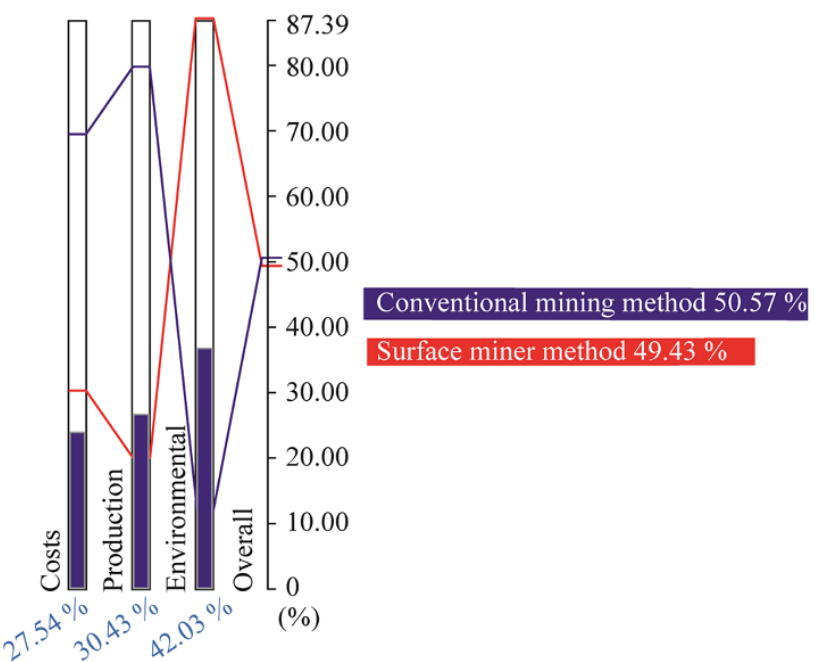

Fig. 7 Sensitivity analysis (SM blasting rating: Good)

Previous sensitivity analysis does not account for variations in rating score input values. Since blasting hazards and material segregation are the highest weighted criteria, a sensitivity analysis of the rating score was performed on these criteria. In this sensitivity analysis, the global weights of the three strategic issues will remain unchanged, while the influence of the rating scores will vary and impact the decision accordingly.

Figure 7 shows the SM mining method score for blasting hazards dropping to "good" with all remaining scores unchanged. Lowering the blasting hazards score for the SM mining method to "good" will affect the selection enough to change the optimal mining method to the conventional mining method with a priority of $50.57 \%$ compared to $49.43 \%$ for the SM mining method.

Finally, Fig. 8 shows the conventional mining method rising to "fair" and the SM mining method dropping to "good" with all remaining scores unchanged. Lowering the blasting hazard and material segregation score for the SM mining method to "good" and raising the conventional to "fair" will affect the selection to the conventional mining method with a priority of $51.48 \%$ compared to $48.52 \%$ for the SM mining method.

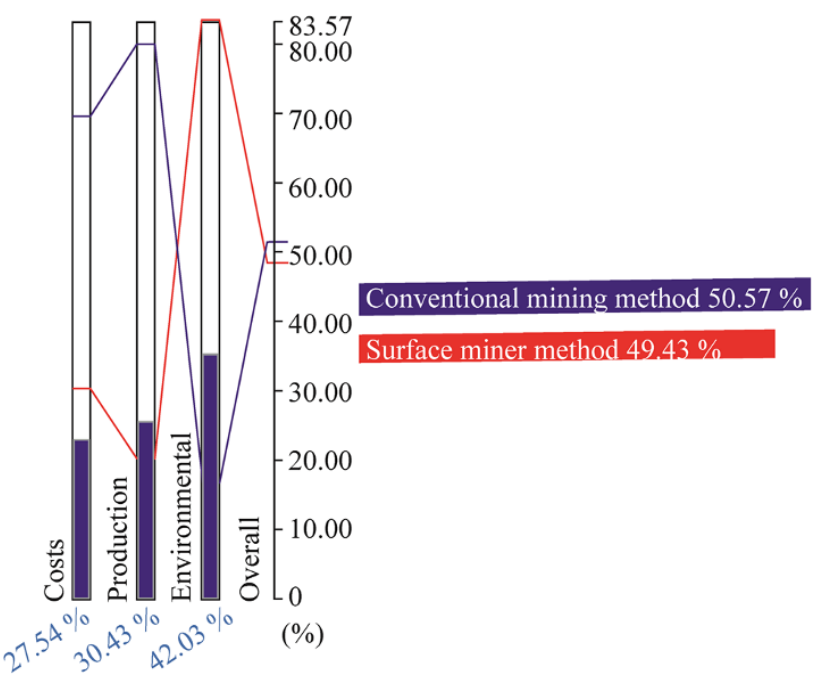

Fig. 8 Sensitivity analysis (conventional blasting and material segregation rating: fair, SM blasting rating: Good)

The results of the sensitivity analysis for the blasting hazards and material segregation score are to be expected as they are the only rating were the SM mining method is superior. By performing these sensitivity analyses, it can be seen how dependent the selection of the optimal mining method is on environmental factors. The combination of the results produced by the cost and production analysis and the application of the AHP, allows for an informed decision on the optimal mining method to be made.

A benefit of introducing SMs to surface coal mining in WV would be an environmental one. If the conditions are favorable and the SM can be applied, most of the blasting processes that concern communities can potentially be eliminated. Specifically, SM usage can eliminate the generation of flyrock, toxic fumes, dust, ground vibration, and surface vibration created by air-blast. While these issues are not so frequent in blasting, the possibility still exists and this is an opportunity to address these environmental issues.

The application of SMs also enables clean cut edges and benches and very stable benched highwalls as opposed to blasted edges. The crushing process provided directly by 
the machine generates an even grade $96 \%<15 \mathrm{~cm}$ of small particle sizes that can either be sold as secondary product (such as road base) or the material could also be used without further treatment for the reclamation process. The elevated grade control by SM eliminates the need of at least the secondary crusher and possibly even (depending on the material) the need for a primary crusher. The SM creates a complete even and smooth surface, which leads to reduced damage to vehicles and tires. The mine operator has continuous control over drainage because the SM is able to cut a slope.

Some of the limitations in this research include the lack of data from a specific mine in WV, absence of the haulage considerations (specifically haul trucks) in the model; and the absence of dragline consideration as a digging and disposal mining unit. These three limitations should be included and addressed in future research.

\section{Conclusions}

Based on the results of the study it can be concluded that the application of the SM would benefit overburden removal from the environmental point of view. The downside of using the SM in surface mining operations begins with the limited quantity of the overburden material being extracted and higher operating cost than conventional mining methods. An application problem arises with higher values of unconfined compressive strength and abrasivity of overburden material. Picks on the cutting drum will wear out faster and require more changes. At a certain point this method becomes unfeasible due to the slower advance rate and cost involved in a high amount of pick changes. New pick changing tools have accelerated this process, but it still remains one of the main factors of the operating cost.

To confirm the results of this research, it is necessary to test a SM in one of the existing surface coal mines in WV. Data collected from the testing should be focused on the engine load factor, the amount of pick wear, cutting depth, and cutting velocity in sandstone and shale overburden and interburden. This would greatly help determine the fuel consumption and maintenance costs involved with the SM. The formulas used for calculation of pick wear would be confirmed or determined to need revision given the data generated from an experimental trial in a material with the known properties.

Acknowledgments The research work in this paper is financially supported by the West Virginia Coal and Energy Research Bureau (CERB). Their contribution is gratefully acknowledged.
Open Access This article is distributed under the terms of the Creative Commons Attribution License which permits any use, distribution, and reproduction in any medium, provided the original author(s) and the source are credited.

\section{References}

Apodaca L (2010) Explosives. In: 2009 Minerals yearbook, United States Geological Survey. U.S. Department of the Interior, Washington, DC

Atlas Copco (2009) Blasthole drilling in open pit mining, 1st edn. Atlas Copco Drilling Solutions LLC, Garland

Austin Powder (2002) Blaster's guide: a resource for the explosives and blasting industry. Austin Powder Company, Inc., Cleveland

Bauer R (2011) Pick wear of a road header. Internal Documentation by Wirtgen, Windhagen

Caterpillar (2010) Caterpillar performance handbook, 40th edn. Caterpillar, Inc., Peoria

Drake R (1990) Bench drilling techniques and equipment selection manual, 1st edn. Ingersoll-Rand, Roanoke, p 85

Hartman HL (ed) (1992) SME mining engineering handbook, 2nd edn. Society for Mining, Metallurgy, and Explorations Inc. Littleton, p 2260

Hartman HL, Mutmansky J (2002) Introductory mining engineering, 2nd edn. Wiley, Hoboken, p 570

InfoMine (2010) Mine and mill equipment costs. InfoMine USA Inc, Spokane Valley, pp SU-2-SU-43

Kennedy BA (ed) (1990) Surface mining. Society for Mining, Metallurgy, and Exploration, Littleton, p 1194

Komatsu (2009) Specifications and application handbook, 30th edn. Komatsu America Corp., Peoria

Nobel Dyno (2009) Explosives engineers' guide. Dyno Nobel, Salt Lake City

Origliasso C (2011) Surface miners: design features and new approaches for performance prediction and costs calculation. Politechnico Di Torino, Tesi di laurea magistrale, Ingegneria per I'Ambiente e il Territorio, p 87

Plinninger R (2010) Hardrock abrasivity investigation using the rock abrasivity index (RAI). Taylor \& Francis Group, London, pp 3445-3452

P\&H Mine Pro (2003) Peak performance practices: excavator selection. Harnischfeger Corporation, Milwaukee

Runge I (1998) Mining economics and strategy. Society for Mining, Metallurgy, and Exploration, Littleton

Rusnak J, Mark C (2000) Using the point load test to determine the uniaxial compressive strength of coal measure rock, Peabody Group, NOISH. In: Proceedings of the 19th international conference on ground countrol in mining. West Virginia University, Morgantown, pp 362-371

Saaty T (1980) The analytic hierarchy process: planning, priority setting, resource allocation. McGraw-Hill International Book Co, New York, p 287

Saaty T (2008) Decision Making with the analytical hierarchy process. Katz Graduate School of Business, University of Pittsburgh, PA. International Journal Services Science. 1(1):83-98

Wirtgen (2010) Wirtgen surface mining manual. Wirtgen Group, Windhagen, p 172

WVGES (2011) Geologic map of West Virginia. Mont Chateau Research Center, West Virginia Geological and Economical Survey, Morgantown 